\title{
JÁ NÃO TE AMO: O QUE FAZEMOS AO CÃO?
}

\section{DO NOT LOVE YOU ANYMORE: WHAT DO WE DO TO THE DOG?}

\author{
YA NO TE QUIERO: ¿QUÉ HACEMOS CON EL PERRO?
}

\author{
Hugo CunHa LançA \\ https://orcid.org/0000-0003-3407-8968 / http://lattes.cnpq.br/1039757637549691 / hdlanca@gmail.com \\ Instituto Politécnico de Beja \\ Beja, Portugal
}

\begin{abstract}
RESUMO
Os animais têm uma nova centralidade na vida social, não sendo a Lei imune ao devir da sociedade. Num tempo em que o amor pelos animais parece incondicional, mas o casamento é a prazo, importa aquilatar sobre o destino do animal de companhia em caso de divórcio. A metodologia de pesquisa utilizada assenta na combinação de três eixos teórico-metodológicos, consubstanciando-se na (i) pesquisa dogmática, no que concerne ao recurso da doutrina, jurisprudência e legislação coeva, (ii) na pesquisa sócio-jurídica, procurando identificar e analisar as incoerências do sistema jurídico relacionando-o com outras ciências como a sociologia e a psicologia, inter alia, e na pesquisa epistemológica, alicerçada no estudo do sistema jurídico no seu todo e das normas jurídicas e dos conceitos jusfilosóficos que o compõem. Com este texto, pretende-se ensaiar soluções para o problema, oferecendo directrizes para o aplicador da lei, tendo por paradigma a realidade e a legislação portuguesa.
\end{abstract}

Palavras-chave: divórcio; animais de companhia; residência.

\begin{abstract}
Animals have a new centrality in social life, and the Law is not immune to the coming of society. At a time when love for animals seems unconditional, but marriage is a term, it is important to assess the fate of the pet in case of divorce. The research methodology used is based on the combination of three theoretical and methodological axes, based on (i) dogmatic research, with regard to the use of doctrine, jurisprudence and current legislation, (ii) in sociolegal research, seeking to identify and analyze the inconsistencies of the legal system by relating it to other sciences such as sociology and psychology, inter alia, and in epistemological research, based on the study of the legal system as a whole and of the legal norms and the jusphilosophical concepts that compose it. With this text, we intend to test solutions to the problem, offering guidelines for the law enforcer, using the reality and Portuguese legislation as a paradigm.
\end{abstract}

Keywords: divorce; animals; residence.

\section{RESUMEN}

Los animales tienen una nueva centralidad en la vida social, y la Ley no es inmune a la llegada de la sociedad. En un momento en que el amor por los animales parece incondicional, pero el matrimonio es un término, es importante evaluar el destino de la mascota en caso de divorcio. La metodología de investigación utilizada se basa en la combinación de tres ejes teóricos y metodológicos, basados en (i) investigación dogmática, con respecto al uso de la doctrina, la jurisprudencia y la legislación actual, (ii) en la investigación socio-legal, buscando identificar y analizar las inconsistencias del sistema legal relacionándolo con otras ciencias como la sociología y la psicología, entre otros, y en la investigación epistemológica, basado en el estudio del sistema legal en su conjunto y de las normas jurídicas y 
los conceptos filosóficos que lo componen. Con este texto, tenemos la intención de probar soluciones al problema, ofreciendo pautas para la aplicación de la ley, utilizando la realidad y la legislación portuguesa como paradigma.

Palabras clave: divorcio animales de compañía; residência.

\section{SUMÁRIO}

INTRODUÇAO; 1 A NOVA CENTRALIDADE DOS ANIMAIS DE COMPANHIA; 2 A CONTEXTUALIZAÇÃO DA QUERELA; 3 A TIPOLOGIA DA RESIDÊNCIA; 3.1 A residência exclusiva; 3.2 A residência unilateral; 3.3 A residência alternada; 4 OS CRITÉRIOS PARA A DETERMINAÇÃO DA RESIDÊNCIA DO ANIMAL DE COMPANHIA; 5 AS QUESTÕES DE PARTICULAR IMPORTÂNCIA SORBE A VIDA DO ANIMAL DE COMPANHIA; 6 A DETERMINAÇÃO DA RESIDÊNCIA DO ANIMAL DE COMPANHIA; CONCLUSÃO; REFERÊNCIAS.

\section{INTRODUÇÃO}

Sou o primeiro a reconhecer que o título é inusitado. Como, tenho empatia por aqueles (e são muitos) que, dominados por preconceitos antropocentristas, consideram que a temática não tem dignidade suficiente para um estudo jurídico. Mas, se assumi o ónus da escrita, fi-lo determinado pela acuidade do tema e da sua centralidade no novo paradigma das relações socioafetivas, porquanto o jurista não pode debruçar-se confortavelmente sobre o mundo das ideias platónicas, antes tem de construir as suas hipóteses, dúvidas e teses em diálogo com a realidade, sentindo o latejar da contemporaneidade, calcorreando, também, as ruelas da vida.

Iniciado o introito sob o manto da exculpação, a premissa subjacente ao artigo é permitir responder a uma singela questão: o que fazer aos animais de companhia no escombro de uma relação, mormente, aquando o divórcio? Para responder ao quesito, analisar-se-ão as diversas modalidades possíveis de residência do animal de companhia e os direitos e deveres dos seus proprietários ${ }^{1}$, procurando oferecer diretrizes para os intérpretes e aplicadores do Direito.

\footnotetext{
1 Utiliza-se a expressão por decorrer do ordenamento jurídico; não obstante, entende-se que a mesma é criticável, sendo preferível o vocábulo "tutor". Assim, Piva e Carreira, p. 2730, em diálogo com TRAPP. PIVA, Rui; CARREIRA, Vinicius. Regulamentação da Guarda e de Convivência com Animais de Estimação. Revista Jurídica Luso-Brasileira, Lisboa, ano 4, n. 6, p. 2719-2741, 2018. Disponível em: http://www.cidp.pt/revistas/rjlb/2018/6/2018_06_2719_2741.pdf. Acesso em: 06 jun. 2020. Para "guardião" vide, inter alia, VIEIRA, Tereza Rodrigues. Biodireito, Animal de Estimação e Equilíbrio Familiar: Apontamentos Iniciais. Revista de Biodireito e Direitos dos Animais, Brasília, v. 2, n. 1, p. 179195, 2016. Disponível em: https://indexlaw.org/index.php/revistarbda/article/view/280/pdf. Acesso em: 06 jun. 2020.

Refira-se que a autonomização do animal de companhia face ao seu proprietário tem tutela na lei penal, nomeadamente na criminalização deste por danos causados àquele, bem como na norma civil que determina que o direito de propriedade de um animal não abrange a possibilidade de, sem motivo legítimo, infligir dor, sofrimento ou quaisquer outros maus-tratos que resultem em sofrimento injustificado, abandono ou morte.
} 
Sem deixar, amiúde, de avaliar criticamente a norma posta, obsequiando o legislador com sugestões axiológicas e hermenêuticas.

\section{A NOVA CENTRALIDADE DOS ANIMAIS DE COMPANHIA}

Há cerca de uma década, um casal desavindo invadiu-me o escritório num fim de tarde a anunciar final da semana. Resolvidos os problemas prementes relacionados com o divórcio e o destino do parco património amealhado, uma questão os dividia: o imenso amor (e utilizo a locução em toda a sua grandiosidade) que os unia ao seu cão, companheiro fiel há mais de cinco anos.

Se, ao tempo, a problemática era espúria e quiçá jocosa, com o devir da pósmodernidade os animais transitaram dos quintais para os quartos e adquiriram uma inaudita centralidade numa sociedade que, carente de afetos, humaniza os animais, não sendo admissível que os juristas insistam em imitar as avestruzes e continuem a enfiar a cabeça na areia. Hodiernamente, num tempo em que o conceito de família assenta nos afetos e em que a norma e a prática reconhecem (e enaltecem) a pluralidade familiar, muitos alegam o surgimento distópico de verdadeiras famílias multiespécies ${ }^{2}$, nas quais os animais são interpretados como partes integrantes do seio familiar, "os filhos de quatro patas"3.

Com efeito, é bastante uma rápida pesquisa pela world wide web para os números nos esmagarem: tendo por paradigma a realidade lusitana, caraterizada pela reduzidíssima natalidade ${ }^{4}$, os donos dos animais de companhia gastam em média $12 \%$ do seu orçamento com estes e existem cerca de 6.2 milhões animais de estimação (mais de 60\% da população!), de acordo com um estudo realizado pela GfK, que mereceu ampla cobertura mediática ${ }^{5}$. Porque as percentagens tendem a perder-se na intermitência dos números, sublinha-se que nos reportamos

\footnotetext{
2 IRVINE, Leslie; CILIA, Laurent. More-than-human families: Pets, people, and practices in multispecies households. Sociology Compass, New York, v. 11, p. 1-13, 2017.

3 CHAVES, Marianna. Disputa de Guarda de Animais de Companhia em sede de Divórcio e Dissolução de União Estável: Reconhecimento da Família Multiespécie? Revista Direito UNIFACS, Salvador, n. 187, 2016. Disponível em: https://revistas.unifacs.br/index.php/redu/article/view/4066/2788. Acesso em: 06 jun. 2020. p. 10.

${ }^{4}$ Salienta-se que vários autores procuram encontrar uma relação de causa efeito entre o aumento do número de animais de companhia e a diminuição do número de filhos; verbi gratia, GARCIA, Francilene. Guarda Compartilhada de Animais Domésticos na Separação Conjugal. 2017. Trabalho de Conclusão de Curso - Faculdade de Direito, Centro Universitário São Lucas, Porto Velho, 2017. Disponível em: http://repositorio.saolucas.edu.br:8080/xmlui/handle/123456789/2118. Acesso em: 05 jan. 2020. p. 5.

${ }^{5}$ PINTO, Sónia Peres. Portugueses gastam mais de 200 milhões de euros por ano na alimentação dos animais. Sapo, Lisboa, 30 jan. 2018. Disponível em: https://sol.sapo.pt/artigo/598602/portuguesesgastam-mais-de-200-milhoes-de-euros-por-ano-na-alimentacao-dos-animais. Acesso em: 10 jun. 2020.
} 
a mais de 200 milhões de euros por ano na alimentação dos animais, aos quais devemos acrescer os gastos com veterinários, roupas, brinquedos e toda uma infinidade de produtos especificamente pensados para os animais, naquela que é hoje uma indústria milionária.

Ciente da nova realidade social, o legislador lusitano (motivado pelas pressões políticas decorrentes de um novo quadro parlamentar do qual consta um partido que tem como principal bandeira a defesa dos direitos dos animais), tem reiteradamente introduzido alterações ao estatuto jurídico do animal, sendo esta a hora dos direitos dos animais ${ }^{6}$.

Assim, a Lei n. ${ }^{\circ}$ 69/2014, de 29 de agosto criminalizou os maus tratos aos animais de companhia e o abandono dos animais de companhia (num ordenamento jurídico em que não é crime o abandono das pessoas idosas). Como a Lei n. ${ }^{\circ} 8 / 2017$, de 3 de março veio estabelecer um novel regime de indemnização em caso de lesão ou morte de animal que se caracteriza por,

segundo a letra da lei, o direito português atribuir uma tutela mais forte em relação ao dano sentimental de um proprietário que vê o seu animal gravemente ferido, do que a uma pessoa que se encontre em posição idêntica, agora já não ante um animal, mas sim um cônjuge, ou um filho ou outros familiares próximos ${ }^{7}$.

Pela sua acuidade, exige referência a nova natureza jurídica dos animais ${ }^{8}$ que veio romper com a secular classificação que distinguia a res da personae. Assim, atualmente, os animais são classificados como um tertium genus, legalmente qualificados como seres vivos dotados de sensibilidade e objeto de proteção jurídica em virtude da sua natureza (art. $201^{\circ}$-B do Código Civil) ${ }^{9}$, premissa que deve nortear todas as reflexões sobre a proteção jurídica dos animais. No entanto, e não obstante estes lampejos de modernidade, em colisão com o regime proposto, a norma posta determina que são aplicáveis subsidiariamente aos animais as disposições relativas às coisas, desde que não sejam incompatíveis com a sua natureza (art. $201^{\circ}$-B do Código Civil). Com data venia, sublimou-se um novo estatuto jurídico, para, num prisma de direito positivo, deixar as coisas exatamente como estavam... Sem problematizar o

${ }^{6}$ ARAÚJO, Fernando. A hora dos direitos dos animais. Coimbra: Almedina, 2003.

7 PEREIRA, André Dias; FERREIRA, Ana Elisabete. Novo Estatuto Jurídico dos Animais em Portugal: Direito Civil e Experimentação Animal. Revista Brasileira de Direito Animal, Salvador, v. 14, n. 1, p. 38-53, 2019. Disponível em: https://portalseer.ufba.br/index.php/RBDA/article/view/30725. Acesso em: 07 jun. 2020. p. 43.

${ }^{8}$ Sobre o tema, vide CHAVES, Marianna. Disputa de Guarda de Animais de Companhia em sede de Divórcio e Dissolução de União Estável: Reconhecimento da Família Multiespécie? Revista Direito UNIFACS, Salvador, $\quad$ n. $187,2016 . \quad$ Disponível em: https://revistas.unifacs.br/index.php/redu/article/view/4066/2788. Acesso em: 06 jun. 2020. p. 7.

9 Criticamente, o Parecer da PGR sublinha que "tal afirmação, se escrita, apesar de óbvia ou independetemente da veracidade científica, filosófica, religiosa, social, ou qualquer outra, revela-se inócua para a extração de quaisquer efeitos jurídicos". 
quesito, porque surge a latere destas cogitações, alegadamente, continua atual o axioma de Protágoras e o homem ainda é a medida de todas as coisas ${ }^{10}$.

Especificamente relevante para o objeto deste estudo é a nova redação do artigo $1775^{\circ}$ do Código Civil, resultante da Lei n. ${ }^{\circ} 8 / 2017$, de 3 de março, que atualmente dispõe:

1- O divórcio por mútuo consentimento pode ser instaurado a todo o tempo na conservatória do registo civil, mediante requerimento assinado pelos cônjuges ou seus procuradores, acompanhado pelos documentos seguintes: a) [...] f) Acordo sobre o destino dos animais de companhia, caso existam ${ }^{11}$.

Consequentemente, se duas pessoas pretendem divorciar-se e estão de acordo nessa pretensão, a mesma está inquinada caso não consigam chegar a acordo sobre o destino dos animais de companhia ${ }^{12}$. Ou, para o fazerem, negam a sua existência, de forma a ser-lhes permitido alcançar o divórcio por mútuo consentimento ${ }^{13}$.

Uma menção final para determinar o objeto deste estudo. Este não tem por objeto todos os animais, mas somente os animais de companhia. Sucede que a lei civil é omissa na sua definição e a explicitação que existe na norma penal suscita diversas ambiguidades. Dessarte, definir animal de companhia como "qualquer animal detido ou destinado a ser detido por seres humanos, designadamente no seu lar, para seu entretenimento e companhia" (art. $389 .^{\circ}$ do Código Penal) ${ }^{14}$, não é imune a uma panóplia de críticas que brevitatis causa apenas elenco: é

${ }^{10}$ Em sentido semelhante, vide o Parecer da Ordem dos Advogados sobre o Estatuto dos Animais. Em sentido não totalmente coincidente, o Parecer do Conselho Superior da Magistratura, sobre os Projetos de Lei relacionados com o Estatuto Jurídico dos Animais sublinha que se este passo pode ter ficado "àquem do desejável, mas não deixa de representar um avanço civilizacional de monte".

11 Uma visão crítica à solução legal foi ensaiada pelo Parecer da PGR sobre o estatuto jurídico dos animais.

12 Sobre o tema, André Dias Pereira e Ana Ferreira alertam que "esta norma pode ser criticável pois cria um obstáculo ao divórcio por acordo de ambos os cônjuges [...] O legislador colocou o bem-estar do animal à frente do interesse facilitação de um divórcio sem litígio, o que não será incorreto se pensarmos que o animal carece de um cuidado diário e de decisões imediatas, não podendo adiar-se as decisões relevantes para um momento ulterior". PEREIRA, André Dias; FERREIRA, Ana Elisabete. Novo Estatuto Jurídico dos Animais em Portugal: Direito Civil e Experimentação Animal. Revista Brasileira de Direito Animal, Salvador, v. 14, n. 1, p. 38-53, $2019 . \quad$ Disponível em: https://portalseer.ufba.br/index.php/RBDA/article/view/30725. Acesso em: 07 jun. 2020. p. 40.

${ }^{13}$ Conforme refere a advogada Sónia Henriques Cristóvão, em BARRETO, Diogo. Casal disputa custódia da cadela. Lei diz que bem-estar do animal "vem sempre no fim". Sábado, Lisboa, 02 out. 2019. Disponível em: https://www.sabado.pt/portugal/detalhe/em-caso-de-divorcio-o-interesse-pelo-bem-estar-doanimal-vem-sempre-no-fim. Acesso em: 07 jun. 2020.

${ }^{14}$ A definição vai beber à Convenção Europeia para a Proteção dos Animais de Companhia do Conselho de Europa, que define animal de companhia como qualquer animal possuído ou destinado a ser possuído pelo homem, para seu entretenimento e enquanto companhia (art. $\left.1 .^{\circ}\right)$. Não obstante, a mesma não é imune a ambiguidades, mormente "a questão de saber se as outras espécies de animais ( $v . g$. pequenos suínos, roedores, répteis, entre outros), que sejam detidas nos termos previstos para os animais de companhia (não sendo, em princípio, tais espécies destinadas a serem detidas por seres humanos)", como sublinha o 
compatível com o novo estatuto dos animais que estes possam ser objeto de detenção? E objeto de direito de propriedade? Pode um animal de companhia ser comprado? Em caso afirmativo, o proprietário é quem o comprou ou quem o cuida? É legítimo, tendo por base os novos cânones, que os animais tenham por função o entretenimento e a companhia dos seres humanos (contrariando o axioma kantiano sobre os meios e os fins?). A detenção de um animal em cárcere privado não contraria múltiplas premissas agitadas pelos defensores dos animais?

Mais: deve-se considerar que são animais de companhia os animais que, não sendo destinados a ser detidos por seres humanos in casu, o são, como um pequeno porco, ainda que não se chame Babe? E aqueloutros, que, sendo destinados a ser detidos por seres humanos, naquele caso concreto, não são utilizados como animais de companhia, mas destinados a outras funções, como será exemplo um cão usado para a caça ou para o pastoreio?

\section{A CONTEXTUALIZAÇÃO DA QUERELA}

Como já se deixou escrito, o problema subjacente a esta reflexão é determinar qual o destino dos animais de companhia em caso de divórcio, anulação do casamento ou rutura da união de facto. Quando os cônjuges desavindos almejam o desejado acordo sobre o destino dos animais de companhia, estudos como este não têm raison d'etre. No entanto, o que fica escrito também significa que, inexistindo este acordo, o jurista deve construir horizontes hermenêuticos que permitam solucionar o diferendo. $\mathrm{E}$, infelizmente, a prática quotidiana expressa a cruel realidade que, em inúmeros casos, os cônjuges desavindos não têm a serenidade emocional para costurar na sua dialética um acordo que tutele quer os seus interesses, quer os interesses do seu agregado familiar - especificamente dos filhos - quer ainda mais os interesses dos seus animais de companhia - que amiúde terminam abandonados à sua triste sorte.

Acresce que a problemática do destino dos animais de companhia, tal qual as querelas sobre o destino dos filhos, sobre a partilha do património comum ou sobre a existência e a definição do valor da prestação de alimentos, inter alia, recorrentemente assumem uma dimensão ontológica e axiológica quer por boas quer por infames razões. Importa deixar imaculado que, com a mesma probidade que invadem os tribunais casais que amam os seus animais de companhia e desejam arduamente continuar a usufruir da sua companhia, que não imaginam o devir sem a sua presença constante, outros reclamam direitos sobre os animais

Parecer do Conselho Superior da Magistratura, sobre os Projetos de Lei relacionados com o Estatuto Jurídico dos Animais. 
movidos por sórdidas razões ${ }^{15}$, mormente o desejo profundo de se vingar do outro e produzir-lhe o maior e mais profundo sofrimento emocional ${ }^{16}$, utilizando o animal como uma arma de arremesso contra o outro.

Com efeito, notícias como "um homem de 38 anos foi detido pela PSP por ter matado, esfolado e esquartejado o cão da ex ${ }^{17}$ " não podem ser imputadas aos nefastos efeitos detetados pela filmologia, culpando-se Glenn Close pelo ato do hediondo cidadão quando a personagem por si interpretada, Alex Forrest, matou o coelhinho da família do homem com o qual tinha cometido adultério e pelo qual se tinha apaixonado sem reciprocidade, no filme Atração Fatal. Para procurarmos razões, mesmo quando a razão as desconhece, teremos de indagar a dimensão moral da natureza humana passível de, com a mesma candura, escrever a llíada e a Odisseia e de bombardear Hiroshima e Nagasaki.

Traz-se o tema à colação, porquanto, quando o profissional do Direito é confrontado com uma querela sobre o destino do animal de companhia é inapto, por falta de poderes extrassensoriais, para discernir se esta disputa se alicerça em sólidas e legítimas motivações ou, pelo contrário, tem por base a perfídia e o egoísmo humano, que também são valores intrínsecos à sua natureza, mormente em momentos de distensões afetivas. Porque o destino dos animais de companhia na ruína do casamento (ou de qualquer outra relação jusfamiliar estável) é uma temática fundamental da vida familiar, esta deveria ser resolvida na intimidade do casal, corolário do primado da autonomia da vida privada, que desconvida a intervenção e regulação dos poderes públicos dada a dimensão pessoal da questão. Assim, extinta a relação, existindo animais de companhia e um desejo comum de os manter, os cônjuges deviam ter a inteligência emocional para ab-rogar divergências e focar as suas inquietações no interesse dos seus animais. Mas, como é axiomático para o cidadão medianamente informado, ou, facto notório, se o leitor

\footnotetext{
${ }^{15}$ Até porque nem todos os animais de companhia são... animais de companhia. Dessarte, "o animal de companhia serve para diferentes papéis, enquanto alguns são considerados membros da família com direitos e privilégios, outros limitam-se ao símbolo de status, ou têm funções meramente decorativas como os peixes, ou recreativas ligadas a hobbies" MEIRELLES, Jussara; FISCHER, Marta. O Animal de Estimação como Membro da Família: repercussões sociais, éticas e jurídicas. In: V CONGRESSO MUNDIAL DE BIOÉTICA E DIREITO DOS ANIMAIS, 2016, Curitiba. Anais dos Congressos de Bioética e Direito Animal. p. 97-110. Disponível em: https://wp.ufpel.edu.br/direitosdosanimais/files/2017/02/Anais-dos-Congressosde-Bio\%C3\%A9tica-e-Direito-Animal-I.pdf?file=2017/02/Anais-dos-Congressos-de-Bio\%C3\%A9tica-e-DireitoAnimal-I.pdf. Acesso em: 07 jun. 2020. p. 102.

${ }^{16}$ Semelhantemente, FERREIRA, Ana Cristina. Da Guarda Compartilhada de Animais e a Dissolução de Relação Afetiva. Monografia (Graduação) - Faculdade de Ciências Jurídicas e Sociais, Centro Universitário de Brasília, Brasília, 2017. Disponível em: https://repositorio.uniceub.br/jspui/handle/235/11683. Acesso em: 07 jun. 2020. p. 54.

17 MARTINS, lúri. Homem mata e esquarteja cão por vingança após fim de relação. Correio da Manhã, Lisboa, 26 dez. 2019. Disponível em: https://www.cm-tv.pt/atualidade/detalhe/homem-mata-eesquarteja-cao-por-vinganca-apos-fim-de-relacao. Acesso em: 07 jun. 2020.
} 
preferir o jurisdicês, inúmeras vezes pelas razões supra mencionadas, os cônjuges falham, sendo incapazes de tecer entre eles uma solução aceitável.

Acresce que, e importa sublimar este ponto, os nossos animais não são nossos, são seres sencientes ${ }^{18}$ com a sua própria idiossincrasia e necessidades específicas, e não máquinas, como dissertava Descartes, pelo que não podemos ignorar a existência de valores de ordem pública. Donde, não pode o Estado desarrogar-se de toda e qualquer responsabilidade remeter a querela para o campo restrito da privatística, pelo que, quando decidiu criar um regime específico para os animais, retirando-lhes o estatuto jurídico de coisas e declarando-lhe uma nova natureza jurídica, objeto de proteção jurídica em virtude da sua natureza deveria, forçosamente, de ter assumido a integralidade das obrigações decorrentes do novel estatuto. Como, compete à doutrina construir armas hermenêuticas que permitam desenhar uma solução boa e justa.

\section{A TIPOLOGIA DA RESIDÊNCIA ${ }^{19}$}

Existindo um corte na relação afetiva, passando os cônjuges a residir afastados um do outro, uma primeira questão, no que concerne a este texto, consiste em determinar onde vai residir o animal de companhia. Assim, e independentemente de a solução ser tecida por acordo ou imposta judicialmente, existe uma trilogia de categorias possíveis ${ }^{20}$ de subscrever sobre o

\footnotetext{
18 Definido no sítio Ética Animal como "a capacidade de ser afetado positiva ou negativamente. É a capacidade de ter experiências. Não é a mera capacidade para perceber um estímulo ou reagir a uma dada ação, como no caso de uma máquina que desempenha certas funções quando pressionamos um botão. A senciência, ou a capacidade para sentir, é algo diferente, isto é, a capacidade de receber e reagir a um estímulo de forma consciente, experimentando-o a partir de dentro". Ou seja, "capazes de ter sentimentos, tais como, de dor, de alegria, de carinho, de afeto, de fome, de tristeza, de abandono". MACHADO, Rosana Marcelino Lourenço. A questão do animal no divórcio litigioso à luz do ordenamento jurídico. Jus, Teresina, 2017. Disponível em: https://jus.com.br/artigos/56075/a-questao-do-animal-nodivorcio-litigioso-a-luz-do-ordenamento-juridico. Acesso em: 07 jun. 2020.

19 O autor discorda frontalmente do recurso ao substantivo "guarda", curial na doutrina, porquanto "a utilização da expressão guarda contribui para a coisificação do animal frente ao ordenamento jurídico, prejudicando ainda mais a aquisição de outros direitos essenciais desses animais" OLIVEIRA, Gabriela. Guarda Compartilhada de Animais Domésticos no Divórcio e na Dissolução de União Estável. Trabalho de Conclusão de Curso (Graduação) - Faculdade de Direito de Vitória, Vitória, 2019. Disponível em: http://191.252.194.60:8080/handle/fdv/702. Acesso em: 07 jun. 2020. p. 24.

${ }_{20}$ Às quais acresce desfazerem-se do animal, como enfatiza a jurista e membro da Comissão Política do PAN, Cristina Rodrigues, em HENRIQUES, Ana. Vai divorciar-se? Tenha cuidado com o cão, e com o gato também. Público, Lisboa, 1 maio 2017. Disponível em: https: / / www.publico.pt/2017/05/01/sociedade/noticia/vai-divorciarse-tenha-cuidado-com-o-cao-e-como-gato-tambem-1770432. Acesso em: 07 jun. 2020
} 
destino dos animais de companhia: estes ficam num sistema de (i) residência exclusiva, (ii) residência unilateral ou (iii) residência partilhada ${ }^{21}$.

Porque utiliza-se odres velhos para vinho novo (e, sublinha-se-o enfaticamente, um vinho bem diferente daquele sobre o que normalmente a querela versa), importa caracterizar dogmaticamente cada uma destas categorias, de forma a construir esta tese alicerçada em bases sólidas.

\subsection{A residência exclusiva}

Sobre a residência exclusiva quer-se trazer à colação o facto de o animal de companhia se tornar propriedade exclusiva de um dos membros do casal. In casu, sepultada a relação afetiva, o animal fica a pertencer a um dos ex-cônjuges (ou, sendo mais do que um animal, estes são divididos entre o casal desavindo, tais como as quinquilharias que faziam parte do património conjugal) perdendo um deles quaisquer direitos sobre o animal. Nesta circunstância, não podem incidir sobre os outros quaisquer deveres, salvo se as partes, através de uma regulação normativa privada, estatuam o contrário.

Com efeito, importa não se deslumbrar com as árvores e esquecer da floresta, como até há pouco mais de uma década as crianças ficavam sempre com as mães, por manifesto interesse dos seus progenitores; o paradigma, ainda, é que o casal em processo de divórcio esteja mais inquieto em decidir o destino das mobílias da casa e outras patrimonialidades que a propriedade dos animais de companhia. Como, em outras situações, o animal pertence apenas a um deles, não se suscitando um libelo sobre o seu destino.

Assim, um caso plausível para a determinação da residência exclusiva é a situação de o animal pertencer apenas a um dos membros do casal, mormente por ter entrado na sua esfera jurídica antes do contrato de casamento. Neste sentido, refira-se que a propriedade dos animais de companhia é uma das exceções à comunicabilidade dos bens entre cônjuges no regime da comunhão geral de bens, tendo o legislador, na alínea h) do art. $1733^{\circ}$ do Código Civil,

\footnotetext{
${ }^{21}$ Não há pejo em reconhecer-se que a analogia que traço entre os regimes possíveis para a residência do animal de companhia e os regimes doutrinal e jurisprudencialmente consagrados para as crianças é suscetível de incomodar alguns leitores, que reputem de inadmissível a equiparação dos animais de companhia aos filhos. Mas, como amiúde repete-se, se o jurista não deve ignorar o plano do dever ser não pode ignorar que habita no mundo do ser, pelo que, mais do que construir valorações morais, deve interpretar a realidade tal como ela é e não como gostaria que fosse. Mais. Este paralelismo que é trazido, como será explanado infra, vai beber a norma jurídica.
} 
expressamente excetuado-a da comunhão, pelo que, por maioria de razão, será um bem próprio nos restantes regimes matrimoniais.

Não obstante o que fica escrito, não é lícito inferir-se destas palavras que sufrage-se uma tese formalista do direito de propriedade do animal de companhia, reconhecendo-se-lhe a propriedade do mesmo, a despeito de quaisquer outras circunstâncias, sempre que uma das partes alegue e prove o seu direito formal de propriedade. A questão é demasiado complexa para simplificações apressadas e de índole meramente formalista, a latere da especificidade concreta de cada caso.

\subsection{A residência unilateral}

Por residência unilateral deve-se entender o status quo de o animal de companhia residir com um dos ex-parceiros, tendo o outro o direito de convívio com o animal ${ }^{22}$. Nesta circunstância, não obstante o animal de companhia ficar a residir com um dos membros do excasal, o outro tem o direito de conviver com o animal, nomeadamente sendo-lhe permitido que o mesmo possa ir assiduamente pernoitar a sua casa, porquanto este convívio não corresponde apenas ao desejo de uma pessoa em manter uma relação de proximidade com o seu animal de companhia, como traduz o desejo e necessidade do próprio animal em conviver com os seus donos $^{23}$, corolário da sua qualificação como ser senciente ${ }^{24}$.

Correspetivamente, o não guardião tem um conjunto de deveres para com o animal de companhia, plasmados na sua relação com o outro, mormente de cariz patrimonial. Dessarte, este deve contribuir para os encargos da vida do animal de companhia, nomeadamente, comparticipar nas despesas com a sua alimentação, veterinário e quaisquer outros gastos que,

22 Evita-se, portanto, utilizar a expressão tradicional (direito de visita), comummente empregue para identificar o feixe de direitos (e obrigações) de um dos progenitores em relação aos filhos aquando da rutura da relação matrimonial. Faz-se-o por um imperativo categórico, por entender ser inadmissível que se procure caracterizar o pai e a mãe como alguém que se limita amiúde a visitar os seus filhos, renegando-se ao direito de exigir a parentalidade e remetendo-se para um obscuro papel na vida da criança.

${ }^{23}$ Sobre o tema, vide MACHADO, Daiana, SANT'ANNA, Aline. Síndrome de Ansiedade por Separação em Animais de Companhia. Revista Brasileira de Zoociências, Juiz de Fora, v. 18, n. 3, p. 159-186, 2017. Disponível em: https://periodicos.ufjf.br/index.php/zoociencias/article/view/24682. Acesso em: 07 jun. 2020.

24 "O neologismo senciente, vem da expressão senciência que é empregada para definir a capacidade dos seres de sentir algo de forma consciente. Ou seja, trata-se da capacidade dos animais serem sensível a tudo o que thes aconteça". COSTA, Deborah; FERREIRA, Fabiano. O Direito dos Animais de Companhia. Revista Brasileira de Direito Animal, Salvador. v.13, n.2, 2018. Disponível em: https://portalseer.ufba.br/index.php/RBDA/article/view/27939/16590. Acesso em: 07 jun. 2020. p. 31. 
justificadamente, o guardião tenha realizado. O cálculo deste valor poder-se-á fazer através da consagração de um valor pecuniário mensal ou equivalente (por exemplo, para a compra de ração, quando esta for a alimentação preferencial do animal), ou através da comparticipação dos valores faturados para fazer face às necessidades do animal ou por um sistema misto que combine ambas as modalidades.

0 que neste contexto se sufraga resulta do novo regime jurídico, no qual o proprietário de um animal "deve assegurar o seu bem-estar, nomeadamente: a) a garantia de acesso a água e alimentação de acordo com as necessidades da espécie em questão; b) a garantia de acesso a cuidados médico-veterinários sempre que justificado, incluindo as medidas profiláticas, de identificação e de vacinação previstas na lei", conforme o art. $1305^{\circ}$-A, do Código Civil, pelo que a obrigatoriedade de pagar uma pensão de alimentos (utiliza-se a expressão no seu sentido técnico-jurídico) tem fundamentação expressa na norma.

\subsection{A residência alternada}

Finalmente, fruto do devir dos tempos, somam-se as situações em que, em paralelo com o que acontece com as crianças (embora no caso dos animais a residência seja alternada e no das crianças partilhada), os proprietários desavindos optam por partilhar o animal entre si através de um sistema em que o animal fica um determinado período de tempo (uma semana, quinze dias, um mês) com cada um deles. Nesta circunstância, devem ainda ser partilhadas as despesas, nomeadamente de saúde, sendo comum que cada um se responsabilize com os gastos com a alimentação no período em que o animal está em sua casa. Refira-se que a opção por um regime de residência alternada está expressamente prevista na letra da lei, mormente no art. $1793^{\circ}$-A, quando se estatui que os animais são confiados a um ou a ambos os cônjuges.

Sendo insofismável que a residência alternada tem o mérito de permitir que cada um dos cônjuges desavindos continue a privar substantivamente com o animal, que mantenha com este os vínculos fortes que construíram durante o tempo em que coabitaram (contrariamente ao sistema da residência unilateral que, muitas vezes, desgasta os laços de afetividade entre o sujeito e o seu animal de companhia e sem os efeitos nefastos que alguns autores apontam à residência partilhada dos filhos que se tornam nómadas entre duas $\operatorname{casas}^{25}$ ), importa

\footnotetext{
${ }^{25}$ Em sentido contrário, pronunciou-se uma médica veterinária consultada para analisar o comportamento de um cão cuja custódia se discutiu num Tribunal português, conforme BARRETO, Diogo. Casal disputa custódia da cadela. Lei diz que bem-estar do animal "vem sempre no fim". Sábado, Lisboa, 02 out. 2019. Disponível em: https://www.sabado.pt/portugal/detalhe/em-caso-de-divorcio-o-interesse-pelo-bem-
} 
compreender que o mesmo nem sempre é faticamente possível. Com efeito, se um deles não tem condições logísticas para alojar satisfatoriamente o animal de companhia em sua casa, se residem geograficamente afastados ou se existe um historial de violência doméstica que torne inaceitável sujeitar um deles à presença nefasta do outro, inter alia, por múltiplas que sejam as virtudes da residência alternada, esta é de repudiar.

\section{OS CRITÉRIOS PARA A DETERMINHAÇÃO DA RESIDÊNCIA DO ANIMAL DE COMPANHIA}

Expostos sumariamente os heterogéneos modelos, importa indagar o que fazer quando inexistir acordo entre os proprietários dos animais de companhia ou, mesmo quando existe esse acordo, este for inapto para tutelar o interesse do animal. Ou, utilizando uma semântica mais curial: como decidir sobre a residência do animal de companhia quando concorrem vontades divergentes?

O legislador oferece uma resposta que em quase nada nos esclarece: "os animais de companhia são confiados a um ou a ambos os cônjuges, considerando, nomeadamente, os interesses de cada um dos cônjuges e dos filhos do casal e também o bem-estar do animal” (art. $1793^{\circ}$-A do Código Civil). Assim, a confiança do animal pode ser atribuída a qualquer um dos cônjuges (ou unidos de facto, porque inexistem razões para uma interpretação restritiva do preceito) tendo como balizas hermenêuticas três valores fundamentais: o interesse de cada um dos cônjuges; o interesse dos filhos do casal; o bem-estar do animal.

Pela sua pertinência, bem como por aquilo que me parece alguma imperícia legislativa, exige-se esmiuçar cada um dos conceitos, procurando densificá-los, preenchendo-os valorativamente.

a) o interesse de cada um dos cônjuges. Mais uma vez (e, enalteça-se a coerência), o legislador expressa uma visão utilitarista do animal, como res ao serviço do seu proprietário ${ }^{26}$.

estar-do-animal-vem-sempre-no-fim. Acesso em: 07 jun. 2020. Com data vénia, o argumento é velho e gasto e foi recorrentemente apreciado criticamente no caso da residência partilhada das crianças e adolescentes.

${ }^{26}$ Para uma crítica assertiva a esta visão antropocêntrica/utilitarista, vide MEIRELLES, Jussara; FISCHER, Marta. O Animal de Estimação como Membro da Família: repercussões sociais, éticas e jurídicas. In: V CONGRESSO MUNDIAL DE BIOÉTICA E DIREITO DOS ANIMAIS, 2016, Curitiba. Anais dos Congressos de Bioética e Direito Animal. p. 97-110. Disponível em: https://wp.ufpel.edu.br/direitosdosanimais/files/2017/02/Anais-dos-Congressos-de-Bio\%C3\%A9tica-eDireito-Animal-I.pdf?file=2017/02/Anais-dos-Congressos-de-Bio\%C3\%A9tica-e-Direito-Animal-I.pdf. Acesso em: 07 jun. 2020. p. 7. 
Evidentemente que não é concebível atribuir o animal de companhia a um dos cônjuges sem que este manifeste desejo e vontade em permanecer com o animal; mas, com data venia, o vocábulo interesse neste contexto não significa um ato declarado de vontade; antes significa ter como paradigma para determinar com quem deverá residir o animal de companhia a conveniência, ganho ou proveito que um dos cônjuges terá e mesurar este seu interesse contrapondo-o ao interesse do outro. Alegadamente, o legislador oferece como primeiro critério deliberativo indagar e mesurar o interesse de cada um dos cônjuges, atribuindo o animal de companhia àquele que alegar e provar ter mais interesse em manter consigo o objeto da discórdia, desconsiderando o interesse do animal ou subjugando-o.

b) o interesse dos filhos do casal. Aplicando-se, mutatis mutandis, o que supra deixouse escrito, terá sido motivação do legislador (o condicional exige-se porquanto, como tende a tornar-se na regra, o diploma está despido de um preâmbulo que ofereça uma baliza interpretativa da lege lata) enaltecer a relevância social para as crianças em conviver com animais. É uma verdade empírica que a latere da decisão de adquirir um animal de companhia encontramos o desejo dos pais para que o filho tenha um amigo e fiel companheiro, somando-se os especialistas que enaltecem as suas múltiplas vantagens para o desenvolvimento integral das crianças $^{27}$. Mas, se o que fica escrito é axiomático, as críticas supra expostas mantêm aqui acuidade, porquanto, sendo certo que grande é a poesia, a bondade e as danças, mas o melhor do mundo são as crianças, tal não pode significar que os seus interesses egoístas devem prevalecer sobre a solução mais adequada ao animal de companhia.

c) o bem-estar do animal. Efetivamente, aquele que devia ser o primeiro (e quiçá) único requisito para determinar a residência do animal de companhia surge em último no catálogo legal. E, neste caso, nem se pode procurar alegar que a ordem seja arbitrária e reconhecer ao anglicanismo last but not least, porquanto o advérbio "e também" com o qual o legislador nos brinda demonstra que a intenção legislativa foi menosprezar, quando analisado comparativamente, este quesito. Mas o texto da lei, sendo pertinente, não pode manietar o intérprete fazendo-o ignorar que, se a interpretação literal é relevante, existem outras ferramentas legislativas que não podemos ignorar, mormente, in casu, a interpretação lógicosistemática e a interpretação teleológica.

\footnotetext{
27 Semelhantemente, alega-se que "o convívio de crianças com animais de estimação faz com que as mesmas se tornem mais afetivas, solidárias, sensíveis, com maior senso de responsabilidade, e faz ainda com que consigam entender melhor a morte". COSTA, Deborah; FERREIRA, Fabiano. O Direito dos Animais de Companhia. Revista Brasileira de Direito Animal, Salvador. v.13, n.2, p. 24-39, 2018. Disponível em: https://portalseer.ufba.br/index.php/RBDA/article/view/27939/16590. Acesso em: 07 jun. 2020. p. 26.
} 
Dessarte, a Lei $n^{\circ} 8 / 2017$, de 03 de março, visa consagrar um estatuto jurídico para o animal procurando fazer o corte epistemológico com uma tradição de dois séculos que dividia o direito entre as categorias de persona e res, através da estatuição do tertium genus os animais $^{28}$. Sendo certo que o legislador não teve a audácia (bom senso?) para dar o passo seguinte e estatuir o Instituto das Pessoas Não Humanas, teceu um regime jurídico que, se distingue os animais das coisas, os aproxima destas, importa não ignorar que este reconhecimento legislativo

teve, assim, por motivos de coerência axiológica-normativa, que alterar o status jurídico civil dos animais, diferenciando-os e autonomizando-os das "coisas", não no sentido de os equiparar às pessoas, mas sim de lhes atribuir um estatuto jurídico que se coadune - minimamente - com a natureza sensível dos mesmos $^{29}$.

Consequentemente, exige-se que o intérprete retire conclusões da premissa, mormente, que reconheça a centralidade do interesse específico do animal de companhia ${ }^{30}$ aquando a decisão de com quem deve residir ${ }^{31}$. Mas, se o que se escreve parece insofismável, a one million dollar question é densificar qual o melhor interesse para o animal, definir quais os critérios que permitem aquilatar o que é melhor para aquele animal de companhia concreto, naquela exata circunstância.

\section{AS QUESTÕES DE PARTICULAR IMPORTÂNCIA SOBRE A VIDA DO ANIMAL DE COMPANHIA}

Um prelúdio que se exige. Independentemente de a solução (seja por acordo, seja judicial) ser atribuir a residência única do animal de companhia a um dos cônjuges ou a residência alternada, o proprietário não guardião não pode ser obliterado da vida do animal e a sua opinião ser irrelevante do devir do seu animal. Com efeito, existem decisões fundamentais

\footnotetext{
${ }^{28}$ Semelhantemente, RAMOS, José Bonifácio. O Animal: Coisa ou Tertium Genus. In: Estudos dedicados ao Professor Doutor Luís Alberto Carvalho Fernandes. v. II. Universidade Católica Portuguesa: Lisboa, 2011, p. 220.

${ }^{29}$ MARQUES, Eduardo Castro. Tertium genus: nem pessoa, nem coisa. Público, Lisboa, 15 maio 2017. Disponível em: https://www.publico.pt/2017/05/15/sociedade/opiniao/tertium-genus-nem-pessoa-nemcoisa-1771933. Acesso em: 07 jun. 2020.

${ }_{30}$ Refira-se que esta é uma obrigação que decorre das obrigações internacionais do Estado português, expressamente prevista no art. $13 .^{\circ}$ do Tratado da União Europeia, por maioria de razão.

31 Em sentido análogo, vide MCLAIN, Tabby. Adapting the Child`s Best Interest model to custody determination of companion animals. Journal of Animal Law, London, v. 6, p. 151-168, 2010.
} 
para a vida do animal de companhia que devem ser assumidas por ambos, por consenso e após diálogo, sendo ilícito que um deles, nestes regimes, se arrogue Senhor do animal de companhia, suprimindo ao outro a expressão da sua vontade.

Também aqui sustenta-se que o caminho será aplicar analogicamente o estatuído para as crianças em caso de divórcio ou de separação judicial de pessoas e bens ${ }^{32}$, previsto no art. $1906^{\circ}$ do Código Civil, que prescreve que "as responsabilidades parentais relativas às questões de particular importância para a vida do filho são exercidas em comum por ambos os progenitores”. Assim, finda a relação afetiva e existindo um animal de companhia que permanece propriedade de ambos, independentemente de ser decidido atribuir-lhe uma residência unilateral ou alternada, as decisões de particular importância devem continuar a ser assumidas por ambos, exigindo-se destes a estabilidade emocional para esquecer aquilo que os afasta e focar-se em torno daquilo que os une, sublimando os legítimos interesses do animal. Porque o facto de já não se amarem (ou um deles já não amar o outro) não os impede de vivenciar um amor comum.

Assumida a premissa, o trabalho de Sísifo é densificar o conceito indeterminado "coisas de particular importância”, concretizando-o através de conceitos apreensíveis pelos cidadãos, porquanto, são estes, e não os juristas iluminados, os destinatários das normas, pelo que o Direito deve ser compreensível pelo cidadão comum. Porque, neste contexto, trabalha-se sem o amparo da jurisprudência nem a rede da doutrina (porquanto, tanto quanto se sabe, o tema não tem sido problematizado), propõe-se realizar um catálogo de circunstâncias que exigem a decisão cumulativa de ambos os proprietários. Assim, são questões de particular importância para a vida do animal de companhia: decisões sobre intervenções cirúrgicas ao animal; a decisão de esterilizar o animal; a decisão sobre procriação; eutanasiar o animal; doar o animal; a mudança de residência do guardião, que tenha consequências significativas para a vida do animal; a utilização comercial do animal; a prática de atividades que envolvam risco para a sua saúde, integridade física e vida; a decisão de vender/doar as crias do animal de companhia.

Por seu turno, o cônjuge que tem consigo o animal tem legitimidade para exercer isoladamente os atos correntes da vida do animal de companhia (e, continua-se a caminhar

\footnotetext{
32 Em sentido semelhante, inter alia, vide JECKEL, Michelle Sanches Barbosa. Guarda compartilhada de animais no divórcio. Lex Magister, Porto Alegre. Disponível em: http://www.editoramagister.com/doutrina_27185510_GUARDA_COMPARTILHADA_DE_ANIMAIS_NO_DIVORC IO.aspx. Acesso em: $19 \mathrm{dez}$. 2019. e MIGLIAVACCA, Carolina Moares; KELLERMANN, Larissa Florentino. A guarda compartilhada dos animais domésticos a partir da dissolução matrimonial: estudo de caso. RKL Advocacia, Belo Horizonte, 27 maio 2019. Disponível em: http://www.rkladvocacia.com/guardacompartilhada-dos-animais-domesticos-partir-da-dissolucao-matrimonial-estudo-de-caso/. Acesso em: 19 nov. 2019.
} 
analogamente com o preceituado para os filhos, in casu no n. ${ }^{\circ}$, do art. $1906 .^{\circ}$, do Código Civil), mormente decidir sobre os horários da alimentação, dos passeios, questões disciplinares ligeiras, ocupação de tempos livres, inter alia. Uma menção final para sublinhar os direitos à informação: o guardião (independentemente do regime de residência) tem a obrigação de informar o outro sobre todos os factos relevantes que ocorram na vida do animal de companhia durante o tempo em que este está à sua guarda $\left(\mathrm{n} .{ }^{\circ} 6\right.$ do. art. $1906 .{ }^{\circ}$, por analogia).

\section{A DETERMINHAÇÃO DA RESIDÊNCIA DO ANIMAL DE COMPANHIA}

Expostos os múltiplos modelos, mencionados os critérios que devem nortear a decisão e na circunstância de inexistir acordo entre os cônjuges (ou este não corresponder ao melhor interesse do animal de companhia ${ }^{33}$ ), importa oferecer ao aplicador da lei alguns critérios passíveis de fundamentar a sua decisão. 0 primeiro passo é indagar a existência de critérios de exclusão $0^{34}$, ou seja, circunstâncias que desaconselhem que determinada pessoa possa ser instituída como guardiã daquele animal de companhia. Será exemplo do que fica escrito a sua condenação penal por crimes praticados contra animais, a utilização do animal em atividades ilícitas, um rasto de negligência no trato do animal. Como, uma enfermidade física ou mental prolongada e grave pode contraindicar, severamente, que o animal the seja atribuído quando inexista no seu agregado familiar alguém com capacidade para desempenhar esta missão. Inexistindo estes critérios de exclusão e concorrendo as vontades dos cônjuges para que the seja atribuído o animal de companhia, deverá o Tribunal indagar se se reúnem as condições que convidam a que a residência seja alternada.

Se sempre pronunciou-se contra um regime legalmente construído que determine como regra ou regime preferencial a residência partilhada dos filhos em caso de divórcio ou rutura de uma relação, no caso dos animais de companhia, dispondo ambos os ex-cônjuges de condições emocionais, económicas e logísticas para a sua residência profícua, defende-se agora que este regime é o preferível. Quando a natureza do animal o permita, porquanto não me parece lógica

\footnotetext{
${ }^{33}$ Semelhantemente, CHAVES, Marianna. Disputa de Guarda de Animais de Companhia em sede de Divórcio e Dissolução de União Estável: Reconhecimento da Família Multiespécie? Revista Direito UNIFACS, Salvador, $\quad$ n. $\quad 187, \quad 2016 . \quad$ Disponível https://revistas.unifacs.br/index.php/redu/article/view/4066/2788. Acesso em: 06 jun. 2020. p. 21 e ss.

${ }^{34}$ Aquilo que, no que concerne às crianças, se denomina de "por uma selecção negativa, isto é, pela procura de aspectos a apontar fortemente contra a atribuição da guarda a um dos pais" SOTTOMAYOR, Maria Clara. Regulação do Exercício das Responsabilidades Parentais em Caso de Divórcio. 5. ed. Coimbra: Livraria Almedina, 2011. p. 41).
} 
que v.g. um aquário ande a viajar entre as residências dos ex-cônjuges para que ambos partilham do peixe que elegeram como animal de companhia.

Inexistindo a possibilidade de a residência ser alternada, o Tribunal será colocado entre Cila e Caríbdis e ser coagido a fazer a escolha de Sofia. Considera-se que a escolha deve ser norteada pelo recurso holístico a um conjunto de critérios, nomeadamente: as condições habitacionais dos cônjuges, nomeadamente quem dispõe de um espaço melhor adaptado ao animal; o cônjuge que tem maior disponibilidade temporal para se fazerem reciprocamente companhia; o cônjuge com o qual residem os filhos; a existência de outros animais de companhia naquele domicílio; a proximidade de parques, praias e outros locais em que o animal de companhia se possa exercitar.

Mas, se todos estes critérios devem ser mesurados, há um que a todos deve sobrelevar: identificar quem é o cônjuge que tem uma relação privilegiada com o animal de companhia, ou seja, com o qual existe um maior grau de afinidade e afetividade. Destarte, se há situações, admite-se que muitas, em que os encargos afetivos com o animal de companhia são partilhados, em muitas outras existe inequivocamente um vínculo privilegiado com um dos cônjuges, aquele que habitualmente passeia o animal, o leva ao veterinário, é responsável pela sua alimentação, que the dá banho e lida com os seus dejetos, que o aninha maioritariamente, ou seja, que no quotidiano desempenha o papel mais significativo na vida do animal de companhia. Sendo possível identificar este sujeito, parece axiomático que este é o principal candidato a ser instituído como tutor (ou guardião) do animal de companhia, mantendo-se uma estabilidade na vida do mesmo. Independentemente de eventuais registos de propriedade (v.g. o Sistema de Informação de Animais de Companhia), porquanto a qualificação do animal de companhia como um tertius genus não permite que, em caso de litígio, se aplique acriticamente as regras do direito de propriedade, objetivando o animal, como um automóvel, um quadro ou uma torradeira, independentemente do facto de o legislador, contrariando os mais atuais axiomas por si mesmo trilhados, continuar a referir-se ao proprietário do animal, importa retirar todas as ilações exegéticas da qualificação do animal como ser vivo dotado de sensibilidade, pelo que o mesmo não pode continuar a ser interpretado como uma mera coisa ao serviço dos desejos egoístas dos seus donos.

Uma nota final. Estas decisões não são eternas e, quando as circunstâncias mudam, é tolice manter as premissas, pelo que a decisão de atribuir a residência do animal de companhia a um ou a ambos não faz caso julgado, sendo sempre possível de ser revista independentemente do silêncio da lei, que estranhamente é omissa sobre a questão. 


\section{CONCLUSÃO}

Termina-se enfatizando algo que viajou abscondido em cada uma das reflexões: não se é destituído da varinha mágica de Circe que habilite o autor a oferecer a solução definitiva para uma querela cuja discussão doutrinal está apenas a iniciar-se. 0 texto que ora finda é apenas um humilde contributo para a desocultação de uma problemática que, apesar de sui generis e que alguns podem reputar de absurda, tem uma centralidade nas novas relações sociais, procurando oferecer um horizonte hermenêutico em que outros possam confiar ou infirmar. Arrogar-se de certezas quando se desbrava um território quase virgem, mais do que soberba, é imbecilidade.

Mas, entre as dúvidas, algumas premissas podem reconhecer-se. A primeira é o reconhecimento de que se está perante uma querela que deve ser resolvida pelo recurso ao casuísmo: cada animal de companhia é um animal de companhia, cada família é uma família. E, como ensinou Tolstoi, se todas as famílias felizes se parecem, cada família infeliz é infeliz à sua maneira. Assim, não se procurem fórmulas matemáticas ou cogitações metafísicas para encontrar respostas para a problemática: averigúe-se caso a caso, animal a animal, família a família, para se permitir concluir qual a melhor solução para cada caso concreto.

Uma segunda premissa foi concluir que dada a frugalidade do texto legal, carregado de lacunas, a indagação de soluções exige uma interpretação analógica, sendo que a regulação das responsabilidades parentais é o melhor paradigma (sem que a analogia corresponda a uma humanização do animal de companhia e, muito menos, a uma animalização das crianças). Por esse facto, este texto caminha em diálogo com a sobeja literatura que versa sobre as responsabilidades parentais, para, deste modo, oferecer bases sólidas para as minhas propostas.

Nesse sentido, com as necessárias adaptações, convocou-se para a discussão a temática da residência do menor as questões de particular importância na sua vida e os critérios doutrinais e jurisprudenciais que regulam a temática aplicando-os mutatis mutandis aos problemas relacionados com a propriedade e a regulação da vida dos animais de companhia, procurando com este texto oferecer ao aplicador do Direito critérios que lhe permitam decidir perante casos concretos.

Porque o jurista não se despe da sua Alma quando escreve nem pode ser acrítico, defendeu-se como premissa que a residência alternada do animal entre os ex-cônjuges será uma solução privilegiada e que, quando esta não for concretizável, o cônjuge não residente mantém 
direitos e deveres sobre o animal de companhia, mormente o direito de visita e o dever de prestar alimentos. Sufragou-se, ainda, que se há uma pluralidade de critérios a ser mesurados, o superior interesse do animal deve nortear as decisões judiciais, assumindo-se como critério primordial.

Sobrepor o interesse do animal de companhia ao interesse dos seus donos soa a absurdo. Mas, se o Jurista deve ter como baliza o Bom, o Belo e o Justo não pode viver acorrentado ao mundo platónico das Ideias, dogmatizando sobre o Mundo Ideal e ignorar o latejar da realidade.

\section{REFERÊNCIAS}

ARAÚJO, Fernando. A hora dos direitos dos animais. Coimbra: Almedina, 2003.

BARRETO, Diogo. Casal disputa custódia da cadela. Lei diz que bem-estar do animal "vem sempre no fim". Sábado, Lisboa, 02 out. 2019. Disponível em: https://www.sabado.pt/portugal/detalhe/em-caso-de-divorcio-o-interesse-pelo-bem-estar-doanimal-vem-sempre-no-fim. Acesso em: 07 jun. 2020.

CHAVES, Marianna. Disputa de Guarda de Animais de Companhia em sede de Divórcio e Dissolução de União Estável: Reconhecimento da Família Multiespécie? Revista Direito UNIFACS, Salvador, n. 187, 2016. Disponível em:

https://revistas.unifacs.br/index.php/redu/article/view/4066/2788. Acesso em: 06 jun. 2020.

COSTA, Deborah; FERREIRA, Fabiano. O Direito dos Animais de Companhia. Revista Brasileira de Direito Animal, Salvador. v.13, n.2, p. 24-39, 2018. Disponível em:

https://portalseer.ufba.br/index.php/RBDA/article/view/27939/16590. Acesso em: 07 jun. 2020.

FERREIRA, Ana Cristina. Da Guarda Compartilhada de Animais e a Dissolução de Relação Afetiva. Monografia (Graduação) - Faculdade de Ciências Jurídicas e Sociais, Centro Universitário de Brasília, Brasília, 2017. Disponível em:

https: //repositorio.uniceub.br/jspui/handle/235/11683. Acesso em: 07 jun. 2020.

GARCIA, Francilene. Guarda Compartilhada de Animais Domésticos na Separação Conjugal. 2017. Trabalho de Conclusão de Curso (Graduação) - Faculdade de Direito, Centro Universitário São Lucas, Porto Velho, 2017. Disponível em: http://repositorio.saolucas.edu.br:8080/xmlui/handle/123456789/2118. Acesso em: 05 jan. 2020. 
HENRIQUES, Ana. Vai divorciar-se? Tenha cuidado com o cão, e com o gato também. Público, Lisboa, 1 maio 2017. Disponível em:

https://www.publico.pt/2017/05/01/sociedade/noticia/vai-divorciarse-tenha-cuidado-com-ocao-e-com-o-gato-tambem-1770432. Acesso em: 07 jun. 2020.

IRVINE, Leslie; CILIA, Laurent. More-than-human families: Pets, people, and practices in multispecies households. Sociology Compass, New York, v. 11, p. 1-13, 2017.

JECKEL, Michelle Sanches Barbosa. Guarda compartilhada de animais no divórcio. Lex Magister, Porto Alegre. Disponível em:

http://www.editoramagister.com/doutrina_27185510_GUARDA_COMPARTILHADA_DE_ANIMAIS_N O_DIVORCIO.aspx. Acesso em: 19 dez. 2019.

MIGLIAVACCA, Carolina Moares; KELLERMANN, Larissa Florentino. A guarda compartilhada dos animais domésticos a partir da dissolução matrimonial: estudo de caso. RKL Advocacia, Belo Horizonte, 27 maio 2019. Disponível em: http: / /www.rkladvocacia.com/guarda-compartilhadados-animais-domesticos-partir-da-dissolucao-matrimonial-estudo-de-caso/. Acesso em: 19 nov. 2019.

MACHADO, Daiana, SANT'ANNA, Aline. Síndrome de Ansiedade por Separação em Animais de Companhia. Revista Brasileira de Zoociências, Juiz de Fora, v. 18, n. 3, p. 159-186, 2017. Disponível em: https://periodicos.ufjf.br/index.php/zoociencias/article/view/24682. Acesso em: 07 jun. 2020.

MACHADO, Rosana Marcelino Lourenço. A questão do animal no divórcio litigioso à luz do ordenamento jurídico. Jus, Teresina, 2017. Disponível em: https://jus.com.br/artigos/56075/aquestao-do-animal-no-divorcio-litigioso-a-luz-do-ordenamento-juridico. Acesso em: 07 jun. 2020.

MARTINS, lúri. Homem mata e esquarteja cão por vingança após fim de relação. Correio da Manhã, Lisboa, 26 dez. 2019. Disponível em: https://www.cm-

tv.pt/atualidade/detalhe/homem-mata-e-esquarteja-cao-por-vinganca-apos-fim-de-relacao. Acesso em: 07 jun. 2020.

MARQUES, Eduardo Castro. Tertium genus: nem pessoa, nem coisa. Público, Lisboa, 15 maio 2017. Disponível em: https://www.publico.pt/2017/05/15/sociedade/opiniao/tertium-genusnem-pessoa-nem-coisa-1771933. Acesso em: 07 jun. 2020.

MCLAIN, Tabby. Adapting the Child 's Best Interest model to custody determination of companion animals. Journal of Animal Law, London, v. 6, p. 151-168, 2010.

MEIRELLES, Jussara; FISCHER, Marta. O Animal de Estimação como Membro da Família: repercussões sociais, éticas e jurídicas. In: V CONGRESSO MUNDIAL DE BIOÉTICA E DIREITO DOS ANIMAIS, 2016, Curitiba. Anais dos Congressos de Bioética e Direito Animal. p. 97-110. 
Disponível em: https: / /wp.ufpel.edu.br/direitosdosanimais/files/2017/02/Anais-dos-Congressosde-Bio\%C3\%A9tica-e-Direito-Animal-I.pdf?file=2017/02/Anais-dos-Congressos-de-Bio\%C3\%A9ticae-Direito-Animal-I.pdf. Acesso em: 07 jun. 2020.

OLIVEIRA, Gabriela. Guarda Compartilhada de Animais Domésticos no Divórcio e na Dissolução de União Estável. Trabalho de Conclusão de Curso (Graduação) - Faculdade de Direito de Vitória, Vitória, 2019. Disponível em: http://191.252.194.60:8080/handle/fdv/702. Acesso em: 07 jun. 2020.

PEREIRA, André Dias; FERREIRA, Ana Elisabete. Novo Estatuto Jurídico dos Animais em Portugal: Direito Civil e Experimentação Animal. Revista Brasileira de Direito Animal, Salvador, v. 14, n. 1, p. 38-53, 2019. Disponível em:

https://portalseer.ufba.br/index.php/RBDA/article/view/30725. Acesso em: 07 jun. 2020.

PINTO, Sónia Peres. Portugueses gastam mais de 200 milhões de euros por ano na alimentação dos animais. Sapo, Lisboa, 30 jan. 2018. Disponível em:

https://sol.sapo.pt/artigo/598602/portugueses-gastam-mais-de-200-milhoes-de-euros-por-anona-alimentacao-dos-animais. Acesso em: 10 jun. 2020.

PIVA, Rui; CARREIRA, Vinicius. Regulamentação da Guarda e de Convivência com Animais de Estimação. Revista Jurídica Luso-Brasileira, Lisboa, ano 4, n. 6, p. 2719-2741, 2018. Disponível em: http://www.cidp.pt/revistas/rjlb/2018/6/2018_06_2719_2741.pdf. Acesso em: 06 jun. 2020.

RAMOS, José Bonifácio. O Animal: Coisa ou Tertium Genus. In: Estudos dedicados ao Professor Doutor Luís Alberto Carvalho Fernandes. v. II. Universidade Católica Portuguesa: Lisboa, 2011, p. 220-256.

SOTTOMAYOR, Maria Clara. Regulação do Exercício das Responsabilidades Parentais em Caso de Divórcio. 5. ed. Coimbra: Livraria Almedina, 2011.

VIEIRA, Tereza Rodrigues. Biodireito, Animal de Estimação e Equilíbrio Familiar: Apontamentos Iniciais. Revista de Biodireito e Direitos dos Animais, Brasília, v. 2, n. 1, p. 179-195, 2016. Disponível em: https://indexlaw.org/index.php/revistarbda/article/view/280/pdf. Acesso em: 06 jun. 2020. 
ISSN 1981-3694

(DOI): $10.5902 / 1981369442753$

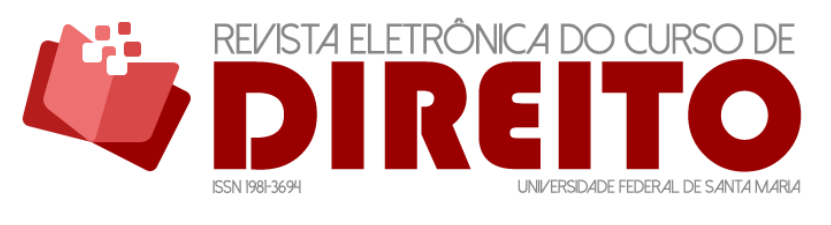

JÁ NÃO TE AMO: O QUE FAZEMOS AO CÃO?

Hugo CUNHA LANÇA

\section{COMO FAZER REFERÊNCIA AO ARTIGO (ABNT):}

LANÇA, Hugo Cunha. Já não te amo: o que fazemos ao cão? Revista Eletrônica do Curso de Direito da UFSM, Santa Maria, RS, v. 15, n. 1, e42753, jan./abr. 2020. ISSN 1981-3694. DOI:

http://dx.doi.org/10.5902/1981369442753. Disponível em:

https://periodicos.ufsm.br/revistadireito/article/view/42753. Acesso em: dia mês. ano.

Direitos autorais 2020 Revista Eletrônica do Curso de Direito da UFSM

Editores responsáveis: Rafael Santos de Oliveira e Angela Araujo da Silveira Espindola

\section{(c) $($ ) $\odot \odot$ \\ BY NC ND}

Esta obra está licenciada com uma Licença Creative Commons Atribuição-NãoComercial-SemDerivações 4.0 Internacional.

\section{SOBRE O AUTOR}

\section{HUGO CUNHA LANÇA}

Professor Adjunto no Instituto Politécnico de Beja, coordenador do curso de solicitadoria e coordenador do gabinete lusófono de direito do IPBeja. Doutor em Direito pela Universidade do Porto, desde 2015 e Investigador Doutorado Integrado no CEDIS - Universidade Nova de Lisboa. 